This is an Accepted Manuscript of an article published by Taylor \& Francis in CURRICULUM INQUIRY on September 2014 (Volume 44, Issue 10 ) available online: http://www.tandfonline.com/ Article DOI: http://dx.doi.org/10.1111/curi.12057

\title{
Relational restorative justice pedagogy in educator professional development Dorothy Vaandering, Ph.D.
}

\begin{abstract}
:
What would a professional development experience rooted in the philosophy, principles, and practices of restorative justice look and feel like? This paper describes how such a professional development project was designed to implement restorative justice principles and practices into schools in a proactive, relational and sustainable manner by using a comprehensive dialogic, democratic peacebuilding pedagogy. The initiative embodied a broad, transformative approach to restorative justice, grounded in participating educators' identifying, articulating and applying personal core values. This professional development focused on diverse educators, their relationships, and conceptual understandings, rather than on narrow techniques for enhancing student understanding or changing student behaviour. Its core practice involved facilitated critical reflexive dialogue in a circle, organized around recognizing the impact of participants' interactions on others, using three central, recurring questions: 'Am I honouring? Am I measuring? What message am I sending?' Situated in the context of relational theory (Llewellyn, 2012), this restorative professional development approach addresses some of the challenges in implementing and sustaining transformative citizenship and peace-building pedagogies in schools. A pedagogical portrait of the rationale, design, and facilitation
\end{abstract}


experience illustrates the theories, practices, and insights of the initiative, called Relationships First: Implementing Restorative Justice from the Ground Up.

There is no way to peace; peace is the way. (A.J. Muste, in Franklin, 2006)

Relationships First: Implementing Restorative Justice from the Ground Up is a professional development experience I planned and carried out with seventeen educators in August 2012 in Newfoundland and Labrador (NL), Canada. It was designed so participants would not just learn about restorative justice in education but also experience its essence and, in so doing, develop capacity to implement its principles and practices in their particular contexts in a sustainable and transformative manner. Intentionally prioritizing relationships encapsulates my understanding of restorative justice as it has grown out of personal experience as educator, researcher, and human being. This article describes the rationale and process of this professional development experience to portray a relational understanding of restorative justice. At a time when restorative justice is being promoted as a "promising initiative to address discipline gaps" that "build(s) trusting, supportive relationships between students and educators" (Skiba, Mediratta, Losen, \& Shabazz, 2014), this comprehensive relational framework challenges the temptation to be objective about restorative justice, as if it were just another approach in education. Describing this experience is as elusive as explaining the organic, sacred process of growth that occurs within a seed when given optimum soil, water, light and warmth. However, as roots emerge to anchor it in place, and a shoot pushes up and out 
from soil into light giving evidence of growth, so this description of professional development endeavours to illustrate the potential restorative justice holds for education.

Relationships First: Implementing Restorative Justice from the Ground Up is a public outreach project made possible through a grant from Social Sciences and Humanities Research Council of Canada. It enabled me to implement the findings of my qualitative doctoral thesis study, which suggested that, if professional development explicitly embodied the philosophical foundation of restorative justice, educators would be better able to engage with it comprehensively in schools. The project and accompanying research are on-going: this paper does not present results but describes the experience, and explores how cultivating pedagogy that embodies the principles and practices of relational restorative justice enacts some foundational values of dialogic, democratic peace-building education.

I begin with a description of how relational conceptions of restorative justice in education developed and then describe how these became the basis for professional development pedagogy. Next, I recount how I facilitated relational restorative justicebased professional development. I conclude with a discussion of how relational restorative justice informs critical, democratic, dialogic professional development, to support transformative peacebuilding education in schools that otherwise are often governed by rules rather than relationships and fear rather than peace (Harber \& Sakade, 2009).

\section{RELATIONAL CONCEPTIONS OF RESTORATIVE JUSTICE}

Originating from ancient spiritual and indigenous traditions, restorative justice entered contemporary societies via the judicial system in the 1970 s as a means for 
addressing harm within communities. Early practice and theory focused on shifting from a preoccupation with "lawbreaking, guilt and punishment, toward a focus on harms, needs and obligations" (Zehr, 2004, p.3). Instead of asking, "What laws have been broken, who did it and what do they deserve" restorative justice asks, "who has been hurt, what are their needs, and whose obligations are these?" (2005). Restorative justice attempts to shift the stance of all involved, from viewing individuals as adversaries to viewing people as interconnected and affected by harm. In its simplest form, this principle is demonstrated in what are usually termed restorative justice conferences or peacemaking circles (Pranis, 2005) — bringing together those harmed, those causing harm, their supporters, and all those affected indirectly by a particular incident. With a facilitator who poses open-ended questions, all share their stories and then collaborate on developing a way to repair the harm. Circles that follow indigenous traditions typically pass a "talking piece" from person to person, symbolically acknowledging each as an honourable participant who is invited to contribute by speaking and listening. Beyond facilitating conflict resolution and sometimes transformation of problems underlying conflict (peace-building), these practices are democratic in that they give voice to diverse stakeholders in decision-making.

Early success of restorative justice initiatives, in particular decreased recidivism and improved family and community relationships (Bradshaw \& Roseborough, 2005), led to adoption of similar practices by educators in alternative schools working with youth involved in crime. When the practitioners involved noted that these school cultures became more hospitable for all, the principles and practices of restorative justice were introduced to mainstream schools (IIRP, 2003; Morrison, 2007). Since the late 1990s, 
pockets of schools across the globe have been working to implement restorative justice. Initially used to address serious behavioural issues and crime within schools, results that included reductions in suspensions and expulsions and improved school climates (Kane, Lloyd, McCluskey, Riddell, Steed \& Weedon, 2007; Reistenberg, 2011b) motivated educators and researchers to examine key elements of the approach. One insight from this work was that when those directly involved in conflicts, their supporters, and representatives from the institution gathered to communicate and listen to one another's perspectives and needs (that is, to sustainably resolve conflicts), it became clear that the reasons for harmful behaviour were often nested within the relationships among the people present as well as more broadly in their social/institutional contexts (Morrison, 2007). In response, restorative justice in schools has grown to encompass a broad continuum of practices, from reactive to proactive, that address the interconnectedness of people within schools (Morrison, 2007; Morrison \& Vaandering, 2012). Such relational restorative justice is holistic and transformative, rooted in aboriginal and other spiritual traditions (Pranis, 2005).

Though many schools continue to use a narrow or reactive approach to restorative justice as post-incident problem solving, others recognize a goal of moving schools' focus from rules to relationships (Hopkins, 2011; Kane, et al. 2007) and replacing social control with social engagement (Morrison \& Vaandering, 2012). The relational practice of restorative justice is comprehensive and proactive, including a continuum of activities often represented as a triangle (below). In theory, facilitating circle conferences to address specific incidents of harm involving a few people should become the tip of the triangle, with the need for such post-incident repair reduced by foundational peace- 
building work where the whole school population is enfolded in building and maintaining and repairing relationships in all aspects of the educational experience.

[Insert Figure 1, Relationship Triangle (adapted from Morrison 2007 \& Hopkins, 2011)] These intensive, targeted and universal restorative justice practices are grounded in a view of humanity as worthy and relational; they affect all aspects of schooling. Thus restorative justice does not stop with interactions involving youth, but includes formal and informal adult interaction in meetings, corridors and lunchroom, the physical space (conducive for dialogue), curriculum content and pedagogy, and so forth. Another way to represent this comprehensive approach is as a continuum of practice in which "reactive" post-incident conflict resolution strategies to repair harm are bracketed by "proactive" democratic peace-building engagement of the adults in the school and the "pro-active" infusion of democratic peace-building pedagogies in classrooms such as class meetings and cooperative learning.

\section{[Insert Figure 2, A Continuum of Practice]}

Theoretical and prescriptive resources promoting restorative justice in education usually advocate proactive and whole-school approaches (Hopkins, 2004; Morrison, 2007). "Whole-school" implies interconnectedness and people's intrinsic need for belonging. However, institutional transformation is complex. Typically grounded in a liberal individualistic paradigm, schools are hierarchical, consequence-driven institutions (Giroux, 1981; Harber \& Sakade, 2009). These structures and beliefs make it difficult to fully develop or sustain whole-school, pro-active, relational culture approaches (Mitchell \& Sackney, 2009). 
Some early proponents of restorative justice warned that restorative justice initiatives risked being co-opted by institutional hierarchies if they focussed only on conflict management procedures after individual incidents, and ignored the necessity of transforming governing structures and relationships (Morris, 1998; Vaandering, 2010). Thus it is not uncommon for elements of some restorative justice professional development to inadvertently reinforce hierarchical power, rather than democratic relationships - for example, by using transmission methods of relaying content, or scripted facilitation questions that manipulate the responses of those blamed for causing harm (McCluskey, 2011; Vaandering, 2013). Practices not clearly grounded in a view of humanity as worthy and interconnected can be rudderless, so that even the most diligent attempts at developing relationships can be side-tracked (Vaandering, 2011).

Restorative justice, in its most comprehensive form as transformative democratic peacebuilding, is a way of being in the world that includes handling potential and actual conflict in communities in an entirely new way. Zehr (2005) calls this a paradigm shift in which people "change the lenses" with which we look at the world, to no longer focus primarily on rules but on people and their needs. In contrast to the predominant liberal individualistic belief that individual people are responsible for their own well-being, this broad understanding of restorative justice is grounded in the conviction that humans are inherently relational (Pranis, 2007) and equally worthy (Bianchi, 1994; Wolterstorff, 2006) — regardless of their capacity, appearance, race, gender, orientation, actions, and so forth. Justice, in this context, is understood more broadly than a judicial definition of justice as retribution - “offenders" receiving what they "deserve." Restorative justice thus attempts to transform communities and schools toward recognizing that people are not 
objects to be manipulated, but rather organic, interconnected, worthy human beings. Rules do not produce healthy relationships; rather, relationships inform the creation of guidelines necessary to nurture human interaction.

As an emerging field, restorative justice practice in judicial and educational contexts has outrun theory (Braithwaite, 2006; Morrison, 2007). An increasing body of research illustrates very broad differences in definitions and practices amongst its proponents (Gavrielides, 2007; Llewellyn \& Howse, 1998). Research showing the positive impact of restorative justice practices in education is usually based on control indicators such as reduced numbers of office referrals, suspensions, expulsions, and teacher/student attendance (Porter, 2007; Stinchcomb, Bazemore, \& Riestenberg, 2006; Youth Justice Board, 2004). Qualitative research findings — examining more fundamental school transformation indicators such as the development of relational ethos, calmer atmospheres and positive student attitudes - tend to be inconclusive and contradictory, and to suggest that many school practices labelled "restorative justice" may (like the traditional practices they purport to replace) focus on behaviour controls and surveillance, equating compliance with responsible behaviour (McCluskey, 2011; McCluskey, Lloyd, Stead, Kane, Riddell, \& Weedon, 2008; Vaandering, 2011). Thus normative visions and pragmatic experiences of restorative justice often exist in tension (Gavrilides, 2007).

My experience as an educator in elementary schools, and now as teacher-educator and researcher in a university, positions me within this tension. I continue to feel the impact of my restorative justice commitments and practices on my relationships with colleagues, students, curriculum, and pedagogy. 
Relational theory (Llewellyn, 2012) has emerged to give voice to what I am now coming to understand as it places the comprehensive, relational restorative justice paradigm in tension with the prevailing context of governing social structures. Relational theory distinguishes between individualistic equality, which currently forms the core of dominant Western perspectives on democracy and justice-a static, ostensibly objective view of the rights of individuals - and relational equality — an organic, living view of people and the world that is at the heart of relational restorative justice. While individualistic equality focuses on material needs and responses to harm experienced by a person in isolation, relational equality identifies respect, concern, and dignity as foundational needs arising from people's connections with one another and their environments. These elements of transformative peace-building (through justice) are reciprocal: if respect, concern and dignity were provided for all by all, then the wellbeing of all people would be nurtured equally and sustainably. The implied shift in thought and action is huge.

\section{RELATIONAL RESTORATIVE JUSTICE AS A BASIS FOR PROFESSIONAL DEVELOPMENT}

As an elementary educator using basic restorative justice practices to develop more effective dialogue between young students and myself, I observed how my pedagogy and curriculum choices were being affected. Intrigued, I began doctoral research to explore what restorative justice looked like, sounded like, and felt like in schools that had adopted its principles and practices. I conducted a critical narrative inquiry, interviewing and observing educators in two Ontario, Canada elementary schools as they implemented different approaches to restorative justice (Vaandering, 2009). My 
thesis research reinforced findings from other jurisdictions (Blood \& Thorsborne, 2005; Morrison, 2007) that the impact of restorative justice practices implemented by individuals, schools, and school districts was varied and often narrow. This challenged me to consider the complexity of variables involved in promoting restorative justice to build sustainable peace.

The educators I interviewed for my thesis study had been introduced in their training to the concept of a paradigm shift embedded in restorative justice, and were drawn to the idea of focusing on the needs of those involved rather than on broken rules. Though most were able to articulate something of this, my observations illustrated that many had not successfully integrated this relational, needs-based perspective into their practice. I found significant variations in understandings of restorative justice, even among educators within the same school who had trained together. This provoked a deeper exploration of the theoretical and philosophical roots of restorative justice (Vaandering, 2011).

Of the 26 educators interviewed during the $\mathrm{PhD}$ research (Vaandering, 2009), one participant from each site stood out as having grasped the relational elements of restorative justice, such that it impacted all aspects of how they lived with their students within the classroom. Tracey and Beth shared stories of experiences with people in their lives who had not fit the norm, who had been tolerated but rarely nurtured by school and social systems. They spoke of defining moments when they had decided to care for and love these people unconditionally, honouring them as valuable, regardless of others' opinions. This led them to view all people in their lives this way. For Tracey, restorative justice training provided by her school board had been like receiving permission to spend 
significant time in class developing a relational culture of belonging for all. Restorative justice training had confirmed for Beth that her work was valuable and now would be supported by her administration. In reflecting on the resonance I felt with restorative justice as relational, I realized that I, too, could identify defining moments where I had acknowledged the beauty and capacity of people, despite systems that had worked to diminish them. However, I also realized how elusive this was- - how one moment I could accept and understand people, while in the next I could judge and dismiss them.

Drawing on a previously developed matrix for behaviour (McCold \& Wachtel, 2003) I began developing one for understanding relationships, articulating the importance of support and expectations in how power influences people's engagement with one another (Vaandering, 2013). This matrix challenged me to consider my expectations for, and support of, the humanity of others.

\section{[Insert Figure 3, Relationship Matrix]}

The relationship matrix articulated that, if I had low expectations and offered low support to people, I was NOT engaged with them and was ignoring their humanity. If I had low expectations but offered high support, I was doing things FOR them, to meet my own emotional needs. If I had high expectations and offered low support, I was doing things TO them, managing them so they would be productive for my own or a broader system's interest. If I could offer high support and high expectations for their vocation of becoming more fully human (Freire, 2005), then I would be engaged WITH them, nurturing their well-being and worth as living humans, not static objects. ${ }^{\mathrm{i}}$ I wondered, how could proponents of restorative justice hold each other and ourselves accountable to 
a transformative, relational vision of being in the world, when our paradigms kept shifting in the face of dominant systems of thought?

I developed three questions to point me toward this core concept of human beings as worthy and relational: "Am I honouring? Am I measuring? What message am I sending?" (Vaandering, 2011). To honour people meant to accept and relate to them, unconditionally, as worthy. In contrast, to measure and judge them in light of my own values would make their worth conditional. I came to understand that, regardless of good intent, my unconditional love and acceptance of people would only be authentically grounded if, in my interaction with them, they felt honoured and not measured. These questions illuminated the foundation of the relationship triangle representing the application of restorative justice theory to schools (Figure 1; Morrison, 2007, p. 158). As a reflective tool for examining various restorative justice practices, the questions shed light on how it could be that some youth participants expressed appreciation for restorative problem-solving circle processes, while others spoke of feeling manipulated by the adults present, and admitted saying what they thought was expected rather than what they really wanted or felt (Daly, 2002; McCluskey, 2013). The questions helped to indicate when restorative justice practices might be manipulated by people and institutional structures that remained (consciously or unconsciously) committed to social control (Daly, 2002; McCluskey et al., 2008; Moore, 2004; Sullivan \& Tifft, 2005).

The three relational questions pointed to what I believed would be necessary for professional development. In my professional and scholarly work, I gravitated towards the few restorative justice professional development resources that emphasized core values (Pranis, 2007; Reistenberg, 2011a). These mirror other school climate initiatives 
that emphasize relational leadership (Hargreaves \& Fullan, 2012) and ecologies of learning (Mitchell \& Sackney, 2009).

If, as I surmised, educators' views of humanity were essential to sustaining transformation, then relational restorative justice professional development would need to be designed such that participants would be challenged explicitly to reflect on their core values and the messages being sent by their own and the school system's practices in terms of what it is to be human. In mainstream schools, educators have often been reduced to technicians rather than autonomous professionals (Giroux, 1988): many things that impact how they engage with their students are considered to be beyond their purview. Thus sometimes educators become resistant to policies imposed by governing authorities, or even to professional development. Would it be possible for participants in this initiative to learn that all people are worthy and relational, despite living in systems that saw people only as deficient individuals, independently responsible for their own success or survival?

\section{PROJECT PORTRAIT: RELATIONAL RESTORATIVE JUSTICE-BASED}

\section{PROFESSIONAL DEVELOPMENT}

Changing paradigms impact all aspects of life. Thus, everything about the professional development project needed to repeatedly point to the worth of all people and their interconnectedness with each other and their environments. I hoped that several participants eventually would form a core group of educators who were committed to restorative justice as a way of being and doing education in their classrooms, schools, and perhaps in the province as a whole. It was a daunting vision and task. In-kind and grant support allowed me to purchase materials, to bring in two educators with extensive 
restorative justice experience (from out of province) as participants, and to invite fourteen Newfoundland and Labrador educators to participate in the two week intensive professional development, plus one week of support and mentoring during the following year.

The following overview of the project describes key aspects of participants, place and program, to illustrate how this professional development initiative embodied a comprehensive relational understanding of restorative justice. Inserted throughout are participant voices, excerpted from focus group interviews conducted six months after the event. All names are pseudonyms, used with permission. ${ }^{\text {ii }}$

Restorative justice intentionally leaves issues in the hands of those most directly involved in conflict, so that solutions emerge from and serve the communities themselves (Christie, 1977, 2013). Thus this professional development project explicitly placed the opportunity for change in the hands of educators, rather than policy makers or department consultants. In May 2012 I issued an invitation to all educators in NL's public schools and various independent educational institutions, in particular to those most closely connected to youth—classroom and itinerant teachers, guidance counsellors, administrators, student assistants. To allow for on-going, immediate support and mentoring for each participant, during and beyond the two-week institute, I invited a pair of educators from each location: this mirrored the significance of supporters in restorative justice conferences.

Interested individuals submitted resumes and statements of interest. Each team also submitted a rationale as to why they felt their school context was suitable for the possibilities that would emerge, and a letter of support from their administrator. I had 
anticipated that it would be difficult to convince educators to give up two weeks of summer vacation. However, over 30 people representing fourteen different institutions applied, and many more inquired: an appetite for such an approach was evident. All submitted convincing rationales for why they should participate. In the end, I selected a cross-section of people from seven institutions, with representation from K-12 grade levels, in the form of vice principals, guidance counsellors, classroom teachers, and an itinerant music teacher. To nurture alternate perspectives and relationships among various types of institutions, I selected a team from an independent faith-based school and one from a social service agency serving youth (aged 12-17) who had dropped out of school. Two of the institutions asked to send (and fund) extra participants, so that a more comprehensive contingent from the school would be prepared. In total, 17 educators attended — balanced in terms of gender (11 female, 8 male), grade level (6 primaryelementary; 6 junior high; 5 high school), and years of experience ( 5 with 5 to 10 years; 6 with 10 to 15 years; 7 over 15 years).

I'm a $200 \mathrm{lb}$ alpha male ... Aggression is part of my personality ... I have never spent two weeks getting to know people from different backgrounds, beliefs, mannerisms, etc. It helped break down those judgmental barriers... it helped me in dealing with people who I don't normally associate with. (Ian, vice principal)

So that participants could imagine restorative justice in a school context, the professional development experience was held in a school, rather than a university or community space. Since school architecture often embodies hierarchical hegemonic ideals (Foucault, 1980), the professional development needed to modify the environment so that everyone was welcomed, could see each other clearly, and would be encouraged 
to engage in dialogue. One of the participating schools offered space that supported relational goals - a large library with round tables in one section, an open section that allowed for an arranged circle of twenty chairs, and doors leading to an outdoor courtyard with benches and picnic tables (Sullivan and Tifft, 2005). Other doors led to a gathering space with kitchen facilities for lunch.

A simple circle without tables honoured participants worth and interconnectedness as human beings and challenged them to take responsibility for their decision to participate. When they arrived Monday morning at 8:30, most were strangers to each other, some were acquaintances. Tentative smiles and greetings over refreshments were polite. When invited to select a chair in the circle, they all came, sat next to the colleague from their institution, and put their belongings behind them. A pot of soil, bowl of seeds, and a talking stick sat poised in the midst of the circle on a woven Mi'Kmaq cloth, all symbols of the history and interconnectedness of restorative justice.

I went in and saw the circle, and I looked at my buddy, and I was like [laughing], "Jeez, A circle!" I had brought my iPad. I had some banking to do. "How are we going to get through ten days of sitting in a circle?" ... We all went in with our preconceived notions of what it was going to be ... (Faye, guidance counselor)

Most later revealed that they had had significant reservations about being present, even though they knew they had accepted the invitation to come. All participants later related how the circles had made them feel vulnerable initially but also immediately cut through their assumptions of what they would experience.

As facilitator, this location and structure reminded me that I was with participants throughout all they were experiencing. As much as they had a responsibility to be present 
with each other, I had the same responsibility. I can still feel the struggle within me, to keep my mouth closed and ears open to really listen to what was being said during discussions. I can also still feel my eyes flitting back and forth between people and place, watching as the openness wove its way around and through us, joining us together as a group.

The [professional development] did reflect the principles of restorative justice ... We got to live it and we got to experience it because we built those relationships with each other. The actual practice supported the theory of restorative justice. (Lori, itinerant music teacher)

Three aspects of professional development that embody the essence of restorative justice were central throughout: (1) participants engaging in a circle process (Pranis, 2007); (2) themes of relationships rippling out from the view of human beings as worthy and relational; and (3) a small card with relational reflection questions. These were combined with time for reflection, role play, dialogue, and inquiry, to knit participants into a group that offered one another respect, concern, and dignity (see Appendix 1 for program overview).

\section{The circle process}

Dialogue circles created opportunity to "do" restorative justice collectively—that is, to grow in our ability to honour one another and contribute to the development of an interconnected relational culture amongst this group. I introduced the circle process immediately after everyone selected a place in the first circle. I explained that though we would be engaged in a variety of activities, the circle would be our primary format for discussion. If all could agree to three guidelines, I would do my best to facilitate dialogue 
so that they would experience safety while learning. These included: (1) If you hold the talking piece you can speak, the rest will listen attentively; (2) You can pass if you want; and (3) Soft eyes turned to wonder (Palmer, 1997). After participants offered suggestions for what 'soft eyes turned to wonder" might mean, I summarized that anything spoken in the circle would be accepted with soft (not critical or hard) eye expressions, reflecting a commitment to wondering what had happened to make a person say something rather than judging. I demonstrated how the talking piece would pass around the circle from person to person consecutively, and how everyone could hold the piece as they spoke or kept a time of silence.

After the group agreed to the guidelines, we began with our first check-in - "What colour are you today?" At this question, several participants laughed with surprise. I smiled, provided fifteen seconds of silent think time for them to consider their response, and then we began. As facilitator of the dialogue, I was also a participant who had the added responsibility for gently reminding anyone (who interrupted or laughed at what was said) of the guidelines to which they had agreed. Everyone shared. ${ }^{\text {iii }}$

As mentioned above, the circle process—including passing a talking piece- has its roots in indigenous cultures (Pranis, Stuart, \& Wedge, 2003). Like seeing the outer shell of a seed, it seems simple yet is nuanced and complex. It embodies the essence of restorative justice principles: it gives every member equal place and time for participation and allows for silence, acceptance of whatever is said as valuable, and opportunities for the introverted to contribute and the extroverted to listen. The open space within the circle holds the words and ideas brought forward. Out of these elements, a collective wisdom can emerge. The discussions can be light or complex and troubling. Facilitating 
the circle dialogue requires an understanding that every aspect of the process can contribute to the development of respect, concern, and dignity for all (Hopkins, 2011; Reistenberg, 2011a).

It gave me the ability to be silent with [my students] ... sometimes we just need them to figure out what they need to say themselves ... it really made me a listener. (Betty, special educator)

It's very easy to forget about, or not be aware of, that power imbalance that exists between an adult and a child, and how you may deal with a particular circumstance, should it arise. ... I don't perceive myself to hold that kind of authority but in actual fact, to a lot of these kids, of course I do. (Greg, guidance counsellor)

These characteristics of relational equality are often elusive in a world that emphasizes individuality. While individual equality can be implemented through measurable distribution and retribution involving material goods and outcomes, relational equality is more complex, and can be experienced only in how people engage with each other. Thus, the professional development experience focused intently on values and processes, not on a set of pre-specified behavioural outcomes.

As I experienced the institute, participants' eyes were bright, their voices excited, and their attention focussed as they shared and responded to each other's stories. They reflected critically on the impact of their own words and deeds, rather than on those of students and colleagues. They saw their own disconnected lives.

\section{Discerning and practicing relational core values}


The project began with, and often revisited, an examination of core values integral to people's well-being. These were then infused in thematic activities where participants individually and collectively explored relationships with self, with other adults, with students, amongst students, with pedagogy and curriculum, and finally with institutional structures. I graphically represented this core idea, of beginning with self and then moving outward, with a series of concentric circles (Figure 4). If the participants could nurture healthy relationships with self and other adults, I expected that they could apply these same attitudes holistically to their relationships with youth and with their environments.

[insert Figure 4, Themes of relationship rippling out from core values]

Given the centrality of enacting core values, in the first two days, I created activities where participants would engage directly with personal values: holding and planting seeds; discussing and displaying eyeglasses created out of cardstock with aspects of their lives that influenced how they saw the world written on the frames; identifying what they each needed from one another to be at their best when together, and creating group guidelines to meet these needs; describing the impact of experiences when they felt they belonged or were alienated; and identifying what they needed from others at times when they had caused or experienced harm. Participants contributed to each activity by writing key ideas on strips of paper and laying them out on the floor in the middle of the circle. This visual, kinaesthetic, and auditory experience encouraged them to examine and organize the ideas collectively rather than merely as individual learners.

Out of these activities, participants explicitly articulated their own core valuessomething they were often expected to know coming into professional development but 
which they had rarely been guided in identifying. As these took shape in the first few days, participants applied their values to various themes of relationship.

We, as individuals, must somehow negotiate/ dialogue with one another to create community. ... I have been used to operating on my own, being responsible to me... [Now] I'm always thinking of my responsibilities to the community...I need to be a part of a community founded on respect, love and understanding. I need to be able to dialogue, to speak my truth and be willing to accord the same to others... It's what we all need as human beings. (Owen, junior high teacher)

My original plan had included, beginning on day three, at least an hour per day when teams from each school would meet to begin planning ways of bringing restorative justice into their particular contexts. In reality, this occurred only on days eight through ten, alongside whole group discussions about how group members could continue to support one another through sharing ideas and developing a website and print resources. The professional development experience that evolved is best described by complexity theory (Davis \& Sumara, 2008): interactions of ideas could lead to yet-unimagined spaces of possibility. I gathered people, provided initial ideas, and allowed time for participants to engage with these individually and collectively. The entire process was not controlled but nurtured, so that the learning was organic rather than mechanical.

[Dorothy, the facilitator] never led in the traditional sense of "I'm the person in charge here." She let it evolve and as it progressed it was interesting to see how the things she said and did, embodied everything she was doing. (Faye, guidance counsellor) 
I adopted the role of a facilitator who disturbs assumptions and status quo to encourage growth (Mitchell \& Sackney, 2009). The main objective of institute activities was that participants experience worth and interconnectedness, in order to create spaces of possibility where relational equality could be realized uniquely in each of the participants' educational contexts.

\section{Relational reflection question card}

I distributed a business-sized card with questions, as a reference point for all participants. There was always a pile available in the middle of the circle, for those who wanted more than one. One side held the broad, philosophy-driven questions discussed above, challenging us to reflect critically on the impact of our interactions with others: “Am I honouring? Am I measuring? What message am I sending?" The other side contained six key restorative practice questions, designed to elicit elements of a storypast, present, and future (Hopkins, 2011): "What happened? What are/were you thinking? What were/are you feeling? What impact has this had on you? What's been the hardest thing for you? What do you need [to do] to move forward?" These were adapted from a set developed for post-incident restorative conflict resolution within a judicial context (O’Connell, Wachtel, \& Wachtel, 1998; RCMP, 1998), to encourage dialogue among those directly and indirectly involved in incidents of harm. When each question is posed by a facilitator, each person is given the opportunity to respond; then, with all perspectives in the open, participants collaborate to find solutions that promote repair and healing.

Personally, I had discovered the versatility of these restorative questions for shaping thinking and dialogue in challenging situations. I used them to guide 
conversations between individuals or groups of people in major or minor conflicts when they confided in me. I used them to shape what I wanted to say to people face-to-face when I was personally involved in conflicts with other adults or with my students as a group. When thinking through personal concerns or frustrations, I answered the questions aloud while I walked alone or wrote in my journal. They guided me as I developed insight into new curriculum content and allowed students to review and synthesize what was recently learned. When my students or I were frustrated, they helped to identify the root of the problem. In any of these situations, simply responding to each question deepened understanding and nurtured a sense of interconnectedness with the world.

I had distributed the cards the first day, after explaining the theory supporting restorative justice. We used them throughout the two weeks—in debriefing after activities; in scenarios where participants took on roles as students, teachers, or colleagues resolving conflicts; in planning for restorative justice implementation in participants' educational contexts. The questions helped show participants how to turn everyday challenges into nurturing experiences by seeing them through a relational lens.

It didn't happen at first. It was something I wanted to do, but I would revert back to my way of being in a fight with my wife or a disagreement with my sister or whatever. Periodically I would remember to bring those [questions] back. It always immediately changed the tenor of the disagreement. It changed how I was, it changed how they were, and it changed how we were as a result, which was good... There was a little bit more of a tenderness around dealing with people who were in my life. (Matt, independent high school teacher) 
I'm proud of my competitiveness. But now when I step back from it I go, "Yeah, but that's an individual thing. How is the community affected? How are the people in my everyday life affected by this?" ... With students we say, "You got a 95, great job; you got a 70, work harder," without looking at the idea of how a class succeeds. I was so comfortable being a person that was comfortable with competition, and now I'm not at all. (Nathan, independent school chaplain)

This question card, like the circle process, might seem deceptively simple. Yet the questions, ordered and combined on one card, were a means of connecting theory with practice. Theory without practice lacks validity, and practice without theory can be dangerous (Morrison, 2013).

\section{RELATIONAL RESTORATIVE JUSTICE: FROM FEAR TO PEACE}

"Relationships first" became somewhat of a mantra for us as a group. It encapsulates the complexity of restorative justice in schools - tied to honouring people as worthy and relational, with youth and adults alike learning and living as a community. The project allowed us to experience this directly, and stood in contrast to the "threat system" (Franklin, 2006) in many schools, which manages people with fear and uncertainty.

In the status quo context of competitive individualism that serves dominant power structures, comprehensive relational restorative justice constitutes a kind of democratic peacebuilding education that challenges and aims to transform this competitive individualism. Here, dissonant voices were not squelched or avoided; rather, people were brought together to engage with one another's stories with respect, concern, and dignity (Banks, 2008; Horner, 2013; Pike, 2012). Restorative justice constitutes democratization 
when it does not promote compliance, but rather disruptive, continuous critique seeking to eliminate prejudice and oppressive power and to nurture empowerment for all (Bauman 2001 in McCluskey, 2013; Freire, 2005).

Restorative justice does not eliminate problems and conflict, but provides a framework for understanding and addressing challenges so that people, communities, and environments are not diminished. "Peace" is the absence of fear during such complex, potentially volatile interaction (Franklin, 2006). Relational restorative justice education recognizes peace and citizenship as processes creating tentative, open spaces pregnant with possibility. It is grounded less in rights and more in responsibility, horizontally holding one another accountable to a vision of well-being.

The key insight relational restorative justice offers to democratic peacebuilding education is the importance of educators developing stances rooted in values of respect, concern, and dignity so that they can encourage students to question the relationships in which they find themselves. Such pedagogy exemplifies democratic peacebuilding because it engages diverse people in speaking for themselves, listening, and making collective decisions for the common good, confronts inequality and prejudice, accepts complexity of identity, and challenges violence. Ultimately it reveals hegemony and stimulates heart. Choice, freedom, support, participation, flexible groupings and space, trust, connection to community, time for reflection, individualized mentoring, and opportunities for agency are key elements of transformative democratic peacebuilding education (Cremin, 2010, 2012). Participants experienced each of these elements throughout the project, while practicing relational equality. 
As the professional development institute came to an end, participants expected me to leave them with steps for implementing restorative justice in their school contexts. However, guided by restorative justice principles and practices, I explained that only they knew their communities and themselves well enough to answer this challenge. If they chose to implement restorative justice in their schools, they would need to translate what they knew into the language of their contexts (Horner, 2013).

Six months after the summer institute, I asked each participant whether there had been something missing in the Relationships First professional development. Karin (primary vice principal) told me she had shared key ideas with her staff by modelling circles in their classes and included them in what she called Caring Harm Awareness Talks (CHATs) to resolve differences with and among students, colleagues, and parents. She wondered aloud how to move things forward more fully:

I didn't get that piece. Or, probably I did get that piece, but I'm afraid to go to that piece because there are fears. ... I need feedback. I want my circle back now with all of them so I can express my emotions and do the project over again.

Thus, instead of elaborating on her fears, Karin identified what she needed to overcome those fears.

The Relationships First project endeavoured to embody fear driven out by love (1 John 4:18). Though we hardly used the words fear and love in our time together, midway through the two weeks, a participant shared the following:

To love someone is to show to them their beauty, their worth and their importance; it is to understand them, understand their cries and their 
body language; it is to rejoice in their presence, spend time in their company and communicate with them. (Vanier, 2001)

Rather than threat systems, schools need to be spaces for love that enact peace as the absence of fear, because peace is indivisible - for any one to have peace, all must have peace (Franklin, 2006). Such a comprehensive, inclusive approach to peacebuilding stands in contrast to more typical "peace" initiatives that emphasize hierarchy, control and compliance. This relational restorative justice professional development was designed for participants to catch a glimpse of, and experience, what could be. 